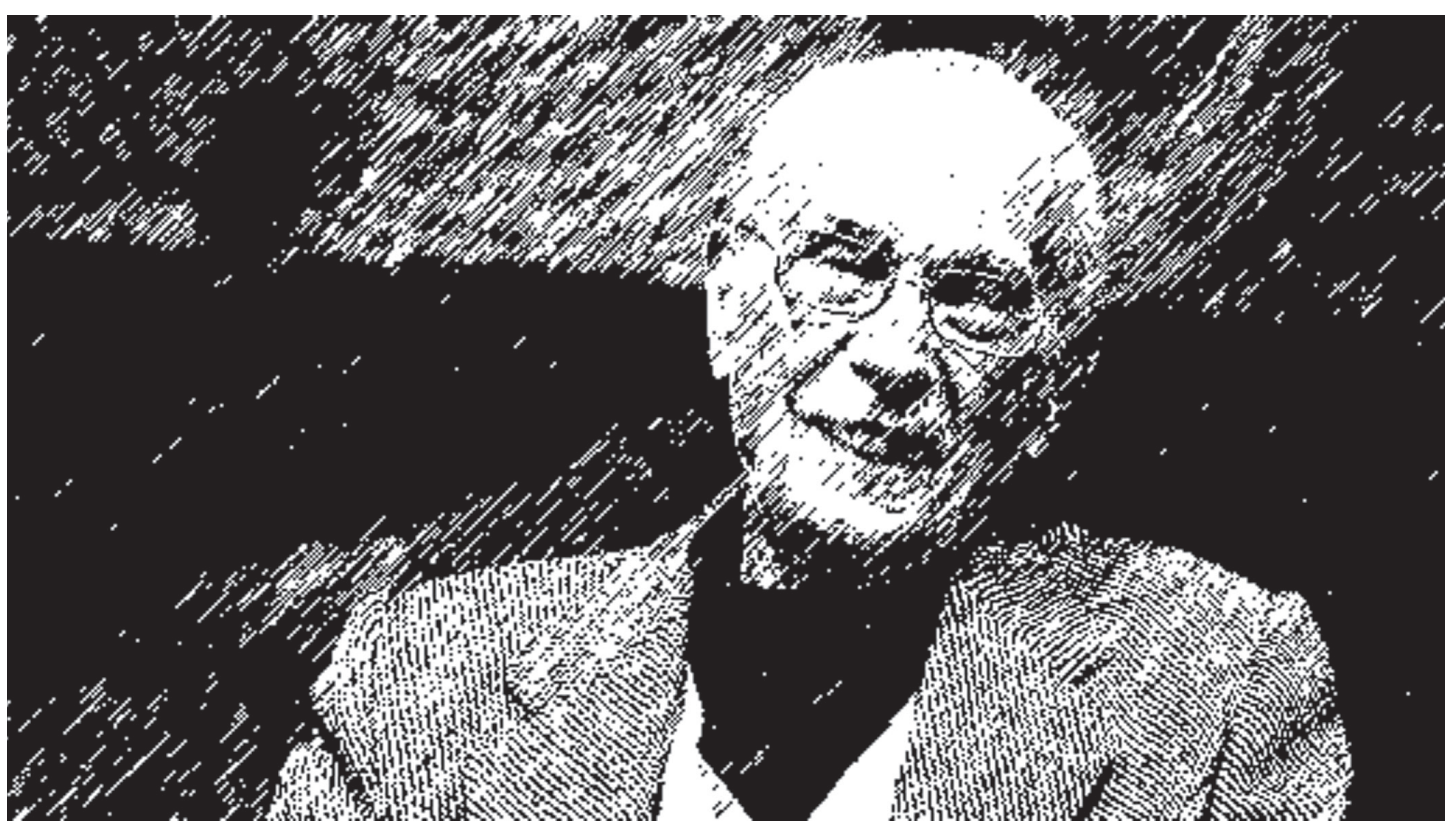

\title{
Na sala de aula
}

\section{com Antonio Candido}

\author{
Marisa Lajolo
}

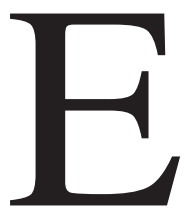

ram os anos 60.

Comecinho da década, 1961, talvez 1962. Quem fazia Letras na USP tinha aulas na Rua Maria

Antonia. Lá ficava a faculdade então chamada Faculdade de Filosofia, Ciências e Letras. Até hoje, o prédio cinzento e sóbrio, com colunas e alguns degraus na entrada, fica de frente para os tijolos vermelhos do Mackenzie. Pertinho, a Faculdade de Arquitetura e Urbanismo (a FAU, na Rua Maranhão) e a Faculdade de Economia (a FEA, na Rua Dr. Vila Nova). Meia quadra abaixo, tinha o Diretório Central dos Estudantes (DCE), ali na Major Sertório.

No currículo dos calouros, aulas de grego para alguns, aulas de línguas e literaturas estrangeiras para outros; aulas de filologia e de latim para todos. E uma novidade: a disciplina teoria literária.

Espanto de alguns dos jovens alunos: então a literatura tinha uma teoria, como a gravidade de Newton ou a relatividade de Einstein?

II

Tendo ou não uma teoria, tinha um professor: Antonio Candido.

A sala dele ficava num prédio ao lado.

MARISA LAJOLO é professora da Universidade Presbiteriana Mackenzie e da Unicamp. 
Prédio de porta estreita, sem as colunas do prédio principal. De sua sala, atulhada de livros, para o prédio das salas de aula, sua figura magra e elegante - sempre de paletó - palmilhava a calçada. Às vezes com o professor Salum (que vestia um avental branco e às vezes um boné), outras com o professor João Alexandre, recém-chegado do Recife.

Era assim que Antonio Candido chegava à sala de aula.

A sala onde ele nos dava aula ficava no andar térreo. Era lá que nós - então moços e moças - travávamos conhecimento com a tal teoria literária, disciplina recém-chegada ao currículo das letras e cuja austeridade do título parecia acenar com objetividade, precisão, rigidez de regras, normas pétreas, imobilidade de categorias.

Puro preconceito!

Não era nada disso que as aulas do professor Antonio Candido nos ofereciam. Para nós, futuros professores e pesquisadores, suas aulas eram um exemplo de docência e de fidelidade a modelos epistemológicos bem menos engessados do que a palavra "teoria" parecia (e parece ainda?) sugerir para as tribos das ciências humanas.

Suas aulas nos proporcionavam uma rara experiência intelectual. Sentíamos que participávamos de situações em que a profunda erudição do professor articulava-se a seu amor à literatura, à sua sensibilidade para o texto literário e a seu respeito por quem assistia a suas aulas. A articulação desses elementos tinha efeitos fantásticos: jamais intimidava os alunos, jamais fazia sentirem-se menores aqueles que não traziam do berço familiaridade com a cultura letrada.

Talvez, até pelo contrário.

Nos incentivava a ler, estudar, pensar.

Era generosa a atenção que o professor dava, ao final de sua exposição, a questões levantadas pelos alunos; e era gentil a paciência com que respondia às nossas abordagens pelos corredores e escadarias.

Esta atenção ao outro - nós, alunos de graduação - articulava-se à extrema clareza com que apresentava e discutia textos e conceitos envolvidos em suas aulas.

Era simples, mas não simplificava o tópico. A complexidade dos temas se esclarecia na explicação demorada, salpicada de expressões que favoreciam interesse e envolvimento. Creio que suas aulas nos faziam sentir que éramos, sim, capazes de ler e de interpretar textos, de nos debruçar sobre a bibliografia, de analisar obras, de discutir autores.

O que não era - e continua não sendo - pouco.

\section{III}

Muitas décadas depois, em uma entrevista (2011, jornal Brasil de Fato ${ }^{1}$ ), o professor comenta e, comentando, parece referendar este seu antigo compromisso com a clareza. O que ele - na entrevista - advoga para textos publicados é o que testemunhávamos e vivíamos em suas aulas.

Diz Antonio Candido, meio século depois de ter inaugurado teoria literária na Universidade de São Paulo:

"Acho que a clareza é um respeito pelo próximo, um respeito pelo leitor. Sempre achei, eu e alguns colegas, que, quando se trata de ciências humanas, apesar de serem

1 A entrevista, na íntegra e com comentários de leitores, está disponível em https://www.brasildefato.com.br/ node/6819. 
chamadas de ciências, são ligadas à nossa humanidade, de maneira que não deve haver jargão científico. Posso dizer o que tenho para dizer nas humanidades com a linguagem comum. [...] acho que a clareza é necessária inclusive para poder divulgar a mensagem, a mensagem deixar de ser um privilégio e se tornar um bem comum.

Uma coisa que sempre me preocupou muito é que os teóricos da literatura dizem: é, preciso fazer isso, mas não fazem".

Seu compromisso com a clareza, tanto nas aulas quanto nos livros, manifesta-se não apenas na fuga ao vocabulário pretensioso e exótico, e às construções retorcidas. A limpidez de seu texto reside, talvez sobretudo, em seu cuidado em pilotar o leitor, por exemplo, sublinhando o ponto de partida e anunciando o pretendido ponto de chegada.

Texto originalmente publicado em $1958^{2}$, já no primeiro parágrafo informa a seus leitores o que esperar e o que não esperar do texto que vão ler:

"Não desejo aqui propor uma teoria sociológica da arte e da literatura, nem mesmo fazer uma contribuição original à sociologia de ambas; mas apenas focalizar aspectos sociais que envolvem a vida artística e literária nos seus diferentes momentos" (Candido, 1975, p. 17).

Como se vê, o fragmento se abre apontando o que não se encontrará no texto (teoria sociológica, nem contribuição original à sociologia); logo depois, a partir de um

2 O rodapé do autor informa que se trata de "redação de uma conferência pronunciada em 1957, na Sociedade de Psicologia de São Paulo" (Candido, 1975). advérbio (apenas), que confere modéstia a quem o emprega, vem a indicação daquilo que, sim, tratará o texto: aspectos sociais que (...).

Ao final do longo e belo artigo, nova cortesia aos leitores: reafirma o objetivo do texto, detalha como chegou a ele (através da literatura), aponta os limites do percurso trilhado (não explica a essência do fenômeno artístico), enumera tópicos importantes discutidos: a formação e o destino das obras. E, de novo, a marca da modéstia representada em algumas expressões: o autor apenas aflorou a questão, pensa ter ficado claro o que expôs e espera que sua exposição ajude a compreender...

"[...] penso ter ficado claro que o estudo sociológico da arte, aflorado aqui sobretudo através da literatura, se não explica a essência do fenômeno artístico, ajuda a compreender a formação e o destino das obras; e, neste sentido, a própria criação" (Candido, 1975, p. 39).

Ou seja, nem verdades categóricas nem certezas pétreas.

\section{IV}

Quase 30 anos depois, em Na Sala de Aula: Caderno de Análise Literária ${ }^{3}$, obra de 1985, a mesma atenuação de certezas e desvio de receitas se fazem claros na exposição dos objetivos do livrinho que, com menos de 100 páginas, Na Sala de Aula pretende "[...] sugerir ao professor e ao estudante manei-

3 A propósito deste livro, retomo ideias que apresentei em artigo publicado no Caderno de Programas e Leituras do Jornal da Tarde em 1985. 
ras possíveis de trabalhar o texto" (Candido, 1985, p. 5).

Analisando poemas brasileiros que foram originalmente apresentados e discutidos em suas aulas, o professor disponibiliza matéria de seus cursos a que alguns tiveram o privilégio de assistir.

$\mathrm{Na}$ análise dos textos, lição preciosa: como olhar e discutir poemas brasileiros de diferentes épocas/estilos? E por que ler e discutir literatura?

Penso que a resposta à questão acima é a grande lição de Antonio Candido.

\section{V}

Ao longo das análises que Na Sala de Aula apresenta, aprendemos que o diálogo de um leitor com um texto constitui um diálogo de muitas vozes: a voz do leitor com o texto que analisa, do leitor com outros leitores daquele texto, do leitor com suas leituras e análises anteriores, etc. Tais leituras tecem-se, na voz que analisa um texto - sobretudo em situações escolares (incluindo as universitárias) - com muitas outras vozes, cuja polifonia como que orienta a sensibilidade de quem (por exemplo, como professor ou como ensaísta), debruçando-se sobre o texto, rege um coro de intérpretes.

A percepção dessas outras vozes (desses outros - os leitores - para os quais seu texto se dirige) se faz presente em $\mathrm{Na}$ Sala de Aula pela consciência da presença virtual de um leitor a pedir-lhe contas.

Ao longo das análises, Antonio Candido não perde de vista seu interlocutor/leitor, a quem credita, em face de seu texto e de cada poema, uma atitude tão ativa quanto a sua. Anuncia suas interpretações: "Caberá uma extrapolação? Se couber, eu diria [...]"
(Candido, 1985, p. 18). Adivinha e leva em conta virtuais antecipações do leitor: "Habituado às neblinas da poesia contemporânea, o leitor fica muito perplexo" (Candido, 1985, p. 22) ou "estes movimentos do poema penetram no subconsciente do leitor devido a uma espécie de sedimentação dos modos e tempos verbais" (Candido, 1985, p. 26).

Creio que é exatamente na intersecção desses diálogos - o do mestre com o texto e o do mestre com seus leitores, debruçados ambos sobre cada poema - que se dá o ato propriamente formador.

Outra lição preciosa de Na Sala de Aula é a de que são muitos os caminhos através dos quais o leitor constrói os significados que, pelo exercício da análise, atribui a um texto. Não se furtando a percorrer nenhum deles, Antonio Candido ensina que a opção por um ou por outro depende do texto, de quem se debruça sobre ele, da situação na qual decorre o exercício de análise, etc.

Assim, recursos à biografia do autor (expulsa há algum tempo das aulas de literatura?), à análise gramatical (vista com severas ressalvas pelos adversários de tendências formalistas da crítica?), à história da elaboração do texto (geralmente relegada ao anedótico?), à minuciosa explicitação da estrutura rítmica e melódica do texto são, em momentos diferentes, convocados para análise dos textos. Para Antonio Candido é o recurso a uma ou outra dessas perspectivas que permite a construção de um significado para o texto.

Na entrevista de 2001, já mencionada, Antonio Candido reafirma a pluralidade de digamos - categorias às quais ele recorre em sua prática de professor e de crítico literário:

"Depois de mais maduro minha conclusão foi muito óbvia: o crítico tem que proceder 
conforme a natureza de cada obra que ele analisa. Há obras que pedem um método psicológico, eu uso; outras pedem estudo do vocabulário, a classe social do autor; uso. Talvez eu seja aquilo que os marxistas xingam muito, que é ser eclético. Talvez eu seja um pouco eclético, confesso. Isso me permite tratar de um número muito variado de obras".

O que - penso - aprende-se em Na Sala de Aula é que discutir ou ensinar literatura não pode ou não deve pautar-se por categorias rígidas apriorísticas que dirijam o rumo que deve seguir cada leitor a cada leitura de cada texto.

Tal redução, no limite, reifica o leitor, a leitura e o próprio texto.

Reificação que talvez seja o oposto do que Antonio Candido propõe como função da literatura.

\section{VI}

A função da literatura é tema constante do professor, ao lado da relação entre literatura e sociedade. Ambos os tópicos são fundamentais para a concepção da literatura como formadora sendo, portanto, um direito de todas as pessoas. Literatura e sociedade, aliás, dão título a uma de suas mais importantes obras (Candido, 2006).

Antonio Candido discute a sutil relação entre o social e o literário a partir da hipótese de que o social, sendo externo à obra, precisa internalizar-se. Esta internalização, por exemplo, é trabalhada na discussão de Memórias de um Sargento de Milícias ${ }^{4}$, no

4 De Manuel Antônio de Almeida (1831-61), Memórias de um Sargento de Milícias foi originalmente (1852-53) publicado em folhetins de A Pacotilha; em 1853 e 1854 foi publicado em livro, em dois volumes. artigo "Dialética da Malandragem", recolhido em O Discurso e a Cidade (Candido, 2004)5.

Comentando a divertida história dos Leonardos e seus parceiros do tempo do Rei, o olhar de Antonio Candido recai sobre a cena em que o prepotente Major Vidigal, na pressa de fazer-se apresentável, veste-se com curiosa indumentária: da cintura para cima, farda fulgurante de medalhas; da cintura para baixo, roupa de casa.

$\mathrm{Na}$ duplicidade das roupas da personagem, o ensaio de Antonio Candido propõe que se veja representada a profunda cisão que marca a sociedade brasileira: digamos que, de um lado, a classe dominante com fumaças francesas; de outro, a grande massa de excluídos. Ricos e pobres, população livre e população escrava, por aí...

Depois de apontar a presença, no texto do romance, de uma dialética da ordem e da desordem (Candido, 2004, p. 31) vem o comentário à vestimenta do Major, que bem pode ilustrar um exercício de interpretação que observa a transformação do externo em interno:

"Há um traço saboroso que funde no terreno do símbolo essas confusões de hemisférios e esta subversão final de valores. Quando as mulheres chegam à sua casa (Dona Maria na cadeirinha, as outras se esbofando ao lado), o Major aparece de chambre de chita e tamancos, num desmazelo que contradiz o seu aprumo durante o curso da narrativa. Atarantado com a visita, desfeito em risos e arrepios de erotismo senil, corre para dentro e volta envergando a casaca do uniforme,

\footnotetext{
5 Ao final do livro, vem a informação de que a análise foi originalmente publicada na Revista do Instituto de Estudos Brasileiros (IEB-USP), n. 8, 1970.
} 
devidamente abotoada e luzindo em seus galões, mas com as calças domésticas e os mesmos tamancos batendo no assoalho" (Candido, 2004, p. 37).

VII

A proposta de interpretação de formas assumidas pela relação entre história \& sociedade, entre o social e o literário encaminha-se sempre para uma concepção da literatura - sua produção e sua recepção - como fator de humanização.

O tema parece aflorar de forma explícita em texto dos anos 70: "A Literatura e a Formação do Homem", que retoma apresentação feita no Congresso da Sociedade Brasileira para o Progresso da Ciência de 1972. Dez anos depois, o tema ressurge, refinado, em "O Direito à Literatura" (Candido, 2004b)7.

Em ambos os textos, o professor propõe que se conceba a literatura como uma resposta a necessidades profunda e ancestralmente sentidas por todos: homens, mulheres e crianças, de todos os tempos e de todos os lugares.

A hipótese do professor é a de que em todas as suas manifestações, das mais simples às mais complexas, a literatura forma e humaniza quem a produz e quem a consome. Forma e humaniza pela fantasia e imaginação de que ela, a literatura, se nutre. $\mathrm{O}$ real da vida, em todas as suas dimensões, é transfigurado pela fabulação.

Medos, desejos, ignorâncias, amores, necessidades, está tudo nela, transfigurado.

6 Disponível em: http://revistas.iel.unicamp.br/index. php/remate/article/view/3560.

7 Inspirado neste texto de Antonio Candido, Aldo Lima organiza a obra O Direito à Literatura (2012).
É através da fabulação que a literatura propõe respostas e refina questões. E, questionando e respondendo, nos forma e humaniza. E por isso é um direito.

Nas palavras de Antonio Candido:

"Assim como todos sonham todas as noites, ninguém é capaz de passar as vinte e quatro horas do dia sem alguns momentos de entrega ao universo fabulado. O sonho assegura durante o sono a presença indispensável deste universo, independentemente da nossa vontade. E durante a vigília a criação ficcional ou poética, que é a mola da literatura em todos os seus níveis e modalidades, está presente em cada um de nós, analfabeto ou erudito [...]" (Candido, 2004b, p. 174).

Mais adiante:

“[...] ela é fator indispensável de humanização e, sendo assim, confirma o homem na sua humanidade, inclusive porque atua em grande parte no subconsciente e no inconsciente" (Candido, 2004b, p. 175).

\section{VIII}

Para finalizar, penso que as observações acima ancoram-se na tese maior de Antonio Candido, a concepção de um sistema literário que costuma ser representado pela figura geométrica de um triângulo cujos vértices simbolizam, respectivamente, autores, obras e públicos.

Apresentado originalmente em Formação da Literatura Brasileira, cuja primeira edição é de 1959, o conceito de sistema literário, sobretudo nas reflexões que instiga sobre as intermediações entre os vértices do triângulo, oferece a fundamentação para a ideia 
da literatura como formadora e, consequentemente, como um direito do ser humano.

$\mathrm{Ou}$, nas palavras de Antonio Candido, com que encerro meu texto:
"A literatura [...] trazendo livremente em si o que chamamos o bem e o que chamamos o mal, humaniza em sentido profundo, porque faz viver" (Candido, 2006b, p. 176).

\section{BIBLIOGRAFIA}

CANDIDO, Antonio. "A Literatura e a Vida Social", in Literatura e Sociedade: Estudos de Teoria e História Literária. 4ª ed. revista. São Paulo, Nacional, 1975. - Na Sala de Aula: Caderno de Análise Literária. São Paulo, Ática, 1985. "Dialética da Malandragem", in O Discurso e a Cidade. São Paulo/Rio de Janeiro, Duas Cidades/Ouro sobre Azul, 2004, pp. 17-46.

"O Direito à Literatura", in Vários Escritos. São Paulo/Rio de Janeiro, Duas Cidades/Ouro sobre Azul, 2004b, pp. 169-91. Literatura e Sociedade. Rio de Janeiro, Ouro sobre Azul, 2006. Formação da Literatura Brasileira. Rio de Janeiro, Ouro sobre Azul, 2006b. LIMA, Aldo (org.). O Direito à Literatura. Recife, Ed. Universitária da UFPE, 2012. 